[Draft - please do not cite without permission, but comments most welcome!]

[Forthcoming in Character: New Directions, Miller, et. al. (eds.), Oxford UP]

\title{
Dispositional Character, and the Value of Acts
}

\author{
Bradford Cokelet
}

Thanks to the virtue ethics movement, moral philosophers now agree that character and virtue are vital topics. Most would agree, for example, that a complete ethical theory must include accounts of moral psychology, character evaluation, moral education, and moral improvement. But this agreement on the importance of having what we might call a 'character module' in one's theory has not led to any sort of general conversion to virtue ethics, understood as a distinctive approach to ethical theorizing as a whole. On the contrary, most moral philosophers accept that we need a character module, but remain perplexed by virtue ethical proposals to assign character (or character evaluations) a more central or prominent role in our ethical theories.

One flashpoint for the dispute is the core virtue ethical thesis that an agent's character can and often does affect the ethical value or deontic status of her acts. If this thesis is false, as a growing number of skeptics contend, then virtue ethical proposals to give character a central or prominent role are effectively hobbled. If character does not affect the value or deontic status of acts, then a theory's character module shouldn't have direct bearing on its action assessment module, and as Crisp (2014) contends, it would be hard to see how virtue ethics could constitute "a third method of ethics" - i.e. a satisfying alternative to various consequentialist and deontological views.

In what follows, I defend the core virtue ethical thesis against the counter-example based attacks marshaled by Hurka (2006), Markovits (2010), and Crisp (2014). In short, I argue that the skeptical attacks on the core virtue ethical thesis hit home if we adopt a reliable trait conception of character, but that by adopting a personal values conception of character, virtue ethicists can rebuff skepticism about their core thesis.

My discussion proceeds as follows. After some introductory comments (section 1), I discuss the reliable trait and personal values conceptions of character and explain how the personal values conception allows us to better defend the core virtue ethical thesis (section 2). I then develop and defend the personal values approach by rebuffing several skeptical attacks 
(section 3) and by sketching accounts of diachronic personal character and aretaic character assessment (sections 4-5).

\section{Preliminaries}

Before getting to the details, some general remarks about my argument are in order. First, as Hurka (2006) rightly insists, any convincing defense of the core virtue ethical thesis must recognize the distinction between an agent's dispositions and the occurrent motives, intentions, and emotions with which she performs some particular act. To see the import of this distinction consider a simpler case involving an inanimate object: a fragile vase is one that is disposed to break if hit with a rock. We can appeal to the fact that it is so disposed in order to predict that it will break before a rock (that someone threw) hits it, and, later, we can appeal to the vase's fragile disposition in order to explain why it broke. Analogously, psychological and behavioral dispositions allow us to predict and explain an agent's occurrent mental states and behavior. Consider Ian, who has an anger issue and is disposed to fly off the handle if he thinks his authority is being publically questioned. By appeal to this dispositional fact about his character, we can predict, before Sue questions his decisions at the next office meeting, that he will fly off the handle and explain why he flew off the handle once he does. ${ }^{1}$

With the distinction between dispositions and occurrent mental states and behavior in hand, the skeptics launch their attack on the core virtue ethical thesis. The thesis states that character can and often does affect the ethical value or deontic status of acts, and since an agent's character is determined by her psychological and behavioral dispositions, the thesis is true only if such dispositions can and often do affect the ethical value or deontic status of acts. And the last mentioned claim is the one that the skeptics reject: they grant that an agent's occurrent psychological states and behavior ${ }^{2}$ can and often do affect the value of her acts, but they deny that the dispositions that are constitutive of the agent's character can have any analogous effect.

\footnotetext{
${ }^{1}$ I remain agnostic about questions about whether psychological dispositions are in some sense reducible to categorical properties of the person's brain or body and about whether agents have some form of free will that makes it impossible to predict with certainty what they will do. ${ }^{2}$ Nothing in my discussion hinges on the talk of states or the list of sample states I give. For example, my arguments could be recast in terms of the reasons for which an agent occurrently acts or in terms of occurrent motivating stances instead of states.
} 
For the sake of argument, I am going to simply grant that an agent's occurrent states do not logically or metaphysically depend on more general dispositional facts about her character. For example, I will grant that a person who is reliably and characteristically disposed to be coldhearted could on some specific occasion feel and act out of great sympathy or empathy. So my thesis here is that dispositional character, understood as something that outstrips the occurrent motives, intentions, and emotions with which an agent acts in a particular case, can and often does affect the ethical value of that particular act.

Next, I should mention that I will focus on (i) claims about the virtue, worth, and moral goodness or badness of acts and leave aside (ii) claims about the moral rightness and wrongness of acts and about whether they are obligatory, permissible, supererogatory, suberogatory, etc. So while the core virtue ethical thesis is that an agent's character can and often does affect the ethical value or deontic status of her acts, I will only be discussing and defending the more restricted thesis that an agent's character can and often does affect the ethical value of her acts. I focus on this restricted thesis for three reasons. First, there are virtue ethicists who follow Anscombe (1958) in thinking that we should abandon the deontic moral concepts (e.g., morally right, morally wrong, and morally obligatory), and the viability of any such non-deontic virtue ethical theory depends on the truth of the restricted thesis. Second, the skeptics to whom I am responding all attack the restricted thesis; they argue that dispositional character does not affect the virtue, worth, or moral goodness of acts. Finally, the question of whether dispositional character can affect the deontic status of an agent's act raises all the issues we will discuss in reference to the restricted thesis but it also raises quite a few more. For example, as mentioned, skeptics about dispositional character affecting the ethical value of acts grant that an agent's occurrent motives and emotions can affect the virtue, worth, or moral goodness of her acts. They only question whether dispositional character can do the same. But when we turn to questions about the deontic status of acts, things are different; some skeptics about virtue ethics deny that even occurrent motives, emotions, and intentions can affect the rightness of acts, so defending the claim that character affects the deontic status of acts is simply a more complicated business than defending the claim that character affects the ethical value of acts. ${ }^{3}$ For all three reasons, I will focus on the restricted thesis about character affecting the ethical value of acts and

\footnotetext{
${ }^{3}$ For relevant discussion of whether motives can affect the deontic status of acts, see Slote (2003), Sverdlik (2011), and Zyl (2012).
} 
leave questions about whether we should abandon the deontic moral concepts or provide a virtue ethical account of them for another time.

With these preliminaries out of the way, I turn to my main argument.

\section{Two Conceptions of Dispositional Character}

To determine whether dispositional character can affect the value of acts, we have to first settle on a conception of character and say something about which dispositions we have in mind when we claim that an agent's character affects the value of her acts. Generally speaking, I think skeptics about the core virtue ethical thesis have assumed a reliable trait conception of character. On this view, an agent's character is constituted by her dispositions to think, act, feel, and navigate her environment in various virtuous and vicious ways, and her character is evaluated by assessing how reliably she is disposed to act, think, and feel virtuously or viciously in various contexts. For example, proponents of the reliable trait conception would assess how characteristically courageous Dan is by figuring out (a) how much courage Dan actually manifests in his occurrent psychological states and behavior and (b) whether he is disposed to behave courageously or not in various situations he could face. Because they are concerned with reliability, they would hold that Dan is more courageous if he disposed to always act courageously on the battlefield than if he is disposed to sometimes exhibit courage and sometimes exhibit cowardice there; and because they are concerned with global reliability, they would hold that he is more courageous still if he is disposed to act well in all fearful circumstances, than if he is disposed to act well in the face of justifiable fear on the battlefield but not in his personal life (e.g. when facing fears of intimacy and commitment).

Given a reliable trait conception of character, the core virtue ethical thesis is quite naturally understood as the thesis that variations in the global reliability of an agent's dispositions to embody virtue and vice can and often does affect the value of her acts. So if we take some act an agent performs, the thesis predicts that the act would be better if the agent were more reliably disposed to virtue and that it would be worse if the agent were more reliably disposed to vice. And this is the view that the skeptical arguments attack.

In order to understand the skeptical arguments, it is important to keep in mind that they target the claim that there is some logical, conceptual, or metaphysical connection between 
variations in dispositional virtue and the ethical value of acts. The skeptics can target that claim while granting that variations in an agent's dispositional reliability to instantiate virtues or vices may be of epistemic importance for act evaluation. For example, consider someone who is reliably disposed to be selfish and heartless. If you are told by a third party that the characteristically selfish and heartless person went out of their way to help a stranger in need, you might find this hard to believe and your knowledge of the person's vicious character might help justify your skepticism. But as the skeptics about the core virtue ethical thesis insist, it may nonetheless be possible for the characteristically selfish and heartless person to act in an out-ofcharacter way, and they go on to ask why such out of character acts are less valuable or good than analogous ones that are performed by people with better character. More specifically, the skeptics contend that someone with reliably vicious dispositions could - at least in principle ${ }^{4}$ - act with occurrent emotions and intentions of the same type that a virtuous person would act with in a situation of the same type, and they then appeal to examples and claim that such out of character (but well motivated) acts are just as virtuous, worthy, and valuable as similar acts performed by people with better dispositional character.

Take Hurka's example of the soldier who dives on a grenade in order to save his comrades and who does so without any ulterior motive, such as a desire for social approbation. Since the soldier knowingly risks his life for a commendable reason, Hurka concludes that his act is courageous. In addition, he claims that its degree of courage and worth (praiseworthiness) is not a function of further facts about how the agent is disposed to act, think, or feel in other situations. He writes:

[I]magine that a military committee is considering whether to give a soldier a medal for bravery. Would they say, 'We know he threw himself on a grenade despite knowing it would cost him his life and in order to save the lives of his comrades. But we cannot give him a medal for bravery because we do not know whether his act issued from a stable disposition or was, on the contrary, out of character'? They would say no such thing, and they would be obnoxious if they did (Hurka 2006, 71-2).

\footnotetext{
${ }^{4}$ Some virtue ethicists fail to clearly distinguish these logical, metaphysical, and epistemic issues, and I believe many arguments for the core virtue ethical thesis are weakened if not undercut by the failure to make the distinction. It may be that there is a logical or metaphysical connection between acting with certain emotions and intentions in a single case and having certain dispositions, but this needs to be established, not assumed. For the sake of argument here I grant that there is no relevant connection.
} 
Now I agree with Hurka that cases like this cast doubt on reliable trait interpretations of the core virtue ethical thesis, but I also think there is an alternative interpretation that is intuitively appealing and that avoids Hurka's attack.

In short, we just need to replace the reliable trait conception of character with a personal values conception. According to a personal values conception, an agent's character is primarily a function of her values and the way those are embodied (or not) in her deliberations, propositional attitudes, feelings, acts, etc. Let me say a bit more about values, in order to fill out the content of the view. ${ }^{5}$ The first thing to mention here is that agents can value a wide variety of objects - e.g., relationships, people, and projects - and that they can also value living up to various standards or ideals - e.g., aesthetic, ethical, or religious. Second, I will assume that valuing something involves integrated cognitive, conative, and deliberative dispositions. For example, if Jane values her friendship with Dan then she believes it is good or important, is disposed to feel sad if the friendship falls apart, is disposed to avoid threats to the friendship, and is disposed to take such threats into account when deliberating about what to do. Third, agents can embody or live up to their values to a greater or lesser degree. Roughly, I hold that when someone fails to fully live up to or embody her values she values the thing cognitively, but deliberates, feels, acts, etc. in ways that are out of line with her evaluative beliefs. Fourth, agents usually value many objects, value some more than others, and can harbor inconsistent or conflicting values. Finally, fifth, when we make comparative judgments about how much someone values an object, we are assessing how well they embody or live up to their values, not just assessing their evaluative beliefs about the object; and how much someone values something depends on her dispositions, not just her occurrent attitudes and behavior in one instance. For example, how much Jane values her friendship with Dan is underdetermined by her sincerely judging on one occasion that it is more valuable (or important to her) than her career advancement. If she actually makes this judgment but is nonetheless disposed to change her judgment and choose, without compunction or regret, her career over the friendship in conflict cases, then she does not actually value it as much as her isolated judgment suggests.

We would need to do a lot more work to develop and defend a full blown personal values conception of character, but for my purposes the very rough sketch of valuing just given will do. What we need to do next is note how the personal values conception can be put to use in

\footnotetext{
${ }^{5}$ My thinking about how to sketch the personal values model is indebted to Scheffler (2011).
} 
interpreting the core virtue ethical thesis and how the personal values interpretation of the thesis differs from the reliable trait interpretation. Now the core virtue ethical thesis tells us that character can and often does affect the value of acts, so if we adopt the personal values conception, then it will entail that the value of an agent's act can and often does vary with changes in her dispositional values. Put otherwise: for some acts that are actually performed, the thesis predicts that they would be better if the agent had had better dispositional values and that they would have been worse if the agent had had worse dispositional values. The exact content of this prediction depends, of course, on the standard one adopts in order to ground claims about someone having better or worse values, but even without introducing any such standard we can illustrate the view, and its appeal, by returning to Hurka's soldier example and considering a specific way in which the soldier's values might be flawed.

The personal values interpretation of the core virtue ethical thesis implies that the soldier's selfless act will vary in courage and worth when the quality of his dispositional values varies. To pick out some relevant values, I suggest we attend more carefully to the natural assumptions we make when we think his act was courageous. As mentioned before, we are assuming that the soldier jumps on the grenade in order to save his comrades, despite knowing that this may cost him his life, and I agree that this makes the act courageous. But note that the description given so far, which focuses on the agent's occurrent intentions or motives, does not tell us anything about how much the agent values his life or well-being. It is possible, for example, that the man does not value his life as he should - he may be disposed to think his life is nearly valueless, to sacrifice it or risk it for various minor goods, to not care when others put his life at risk, etc. And reflection on this case reveals just what the core virtue ethical thesis predicts: the degree of virtue, worth, and value of the soldier's heroic act of jumping on the grenade (to save his comrades) is greater if he aptly values his life than if he does not. Other things being equal, it is more courageous, admirable, and good to knowingly risk something of great personal value than it is to risk something that is, in fact, of great value but that you erroneously take to be a minor good.

We have just seen that the personal values interpretation of the core virtue ethical thesis has plausible implications for Hurka's soldier case, and I will shortly turn to some further skeptical cases. Like Hurka's, the other skeptical cases involve interactions between strangers who are in what we might call "dire straights," and, although I do think the strategy just deployed 
on the first Hurka case can be applied in many cases of this type, I want to straightforwardly admit that in some extra-ordinary cases involving strangers an agent's personal values will have little to no affect on the value of his acts. Admitting this is, however, no embarrassment for the virtue ethicist because it is compatible with the truth of the core virtue ethical thesis; we can admit that dispositional values have no affect on acts in some cases while maintaining that they can and often do affect the value of acts more generally. For example, the virtue ethicists can point out that dispositions affect the value of acts both in some extra-ordinary cases, such as Hurka's, and, as I will now argue, in numerous ordinary cases involving people who are substantively related.

To see the pervasive influence of dispositional values on the value of acts in ordinary circumstances, we need only turn to cases in which the value and worth of an agent's act is a function of its interpersonal meaning. ${ }^{6}$ The basic idea is that when people are substantively related to us, i.e. they are our friends, parents, bosses, etc. and not just strangers, we care a lot about what they think and feel about us and how much they value us and our relationships with them. By extension, the acts that these people perform have interpersonal meaning to the extent that they embody, communicate, or signify what these people think and feel about us and how much they value us and our relationships.

Take Randy, who shows up at his son's soccer game in order to support him, and who feels love and pride as he watches his son from the sideline. Showing up to watch is in this case a good, kind thing to do. Randy's act speaks well of him and both he and his act are worthy of praise. But, as the personal values view suggests, the ethical value of Randy's act will nonetheless wax and wane with the quality of his dispositional values. For example, we might naturally assume that Randy's act is in character in the sense that his motives, intentions, and emotions in this one case reflect his personal values - we might assume that he values his son and their relationship and that for this reason he is disposed to support and love him in various situations. But, of course, it is also possible that Randy is acting on out-of-character intentions when he comes to his son's game. It is possible that, while he genuinely intends to support his son on this one occasion, he does not value his son and their relationship very much and for this reason he is not reliablely disposed to love and support him. For example, if Randy's friends had invited him to watch the ball game and get drunk at the bar, he would never have showed up at

\footnotetext{
${ }^{6}$ My thoughts about interpersonal meaning are influenced by Scanlon (2010).
} 
the game, and he would have felt no regret or guilt about not showing up; if asked he would say that "quality time" with kids is over-rated and that he would prefer to party with friends or even put in some overtime at work. The point is that the value and worth of Randy's showing up (for good reasons) will wax and wane with his overall values; his act of showing up will "mean less" and be less good and praiseworthy, if he is a bad dad than if he is a good one. And this is just what the core virtue ethical thesis predicts on the personal values interpretation.

Before moving on to consider some further skeptical cases, I want to highlight the difference between the personal values interpretation and the reliable trait one. To do so, I want to explain why the moves I have just made in response to Hurka's skeptical case are not available to us if we adopt the reliable trait conception of character instead of the personal values conception. It might seem that proponents of the reliable trait conception could point out that if Hurka's soldier does not value his life as much as he should, then he will have the dispositional vice of imprudence, and that if Randy is a bad dad that is because he has the dispositional vices of disloyalty and heartlessness. Now in general I think that there is something right about this form of response. In particular, I agree with the dispositional vice claims just made. But the important point for our purposes is that the response will not save the reliable trait approach. Let me explain.

The reliable trait conception I sketched at the outset emphasizes the importance of being globally virtuous or vicious and this suggests, for example, that Randy's act would have more value if he exhibited loyalty in a variety of contexts than if he did not; and this is a mistake. The value of his act may well be affected by how loyal and sympathetic he is disposed to be towards his son, but that is because his degree of dispositional loyalty and sympathy in this bounded context embodies, communicates, or signifies how much he values his son and their relationship. By the same token, variations in Randy's global loyalty or sympathy will not be reliably correlated with variations in the value of his act and that is because variation in global loyalty and sympathy may have no substantive connection to how much he values his son and their relationship. So while variations in reliable character may well affect the value of acts, this is true only when (and because) the variations in reliable character reflect variations in the personal values that are relevant in the local context. And this is just what the reliable trait conception of character fails to adequately acknowledge, and what the personal values conception is designed to highlight. 


\section{Three More Skeptical Cases}

I have argued that the personal values version of the core virtue ethical thesis yields intuitive results in ordinary cases and that, unlike the reliable trait version of the thesis, it avoids Hurka's soldier counter-example. In this section, I want to look at three more cases that skeptics take to cast doubt on the core thesis, and explain how to accommodate them. Consider, first, two cases involving strangers in dire need

Ronnie and Reggie are vicious gangsters. They are equally ready to kill, torture, and terrorize people, and do so to the same extent. On one occasion, both of them are confronted by someone whose life is in danger and needs help. For some reason (perhaps her perfume reminds him of a past girlfriend), Ronnie feels sorry for this individual, and finds it easy to help her, thereby acting in an entirely uncharacteristic way. Reggie, as usual, does nothing to help (Crisp 2014: 14).

If a fanatical dog-lover performs a dangerous rescue operation to save a group of strangers, at great personal risk, should we discount the worthiness of his actions because, had his dog required his heroics at the same time, the dog-lover would have abandoned the strangers? That he would have done so may be a sign of excessive concern for the dog, rather than of too little concern for the strangers - after all, the dog-lover was willing to risk his own life to save theirs. And given that the dog was not present to deflect our hero's attention from the reasons he had to perform the rescue, it seems ungenerous to withhold praise for so admirable an act simply because the dog might have been present (Markovits 2010: 210).

As mentioned, I think that defenders of the core virtue ethical thesis should simply grant that in some cases the agent's dispositions have little or no bearing on the value, degree of virtue, or praiseworthiness of her acts, and I will grant, for the sake of argument, that Crisp's case is one of these. Regarding Markovits' case, however, there are two points to make. First, as in Hurka's soldier case, the value, virtue, and praiseworthiness of the dog lover's actions would be affected by how much he (dispositionally) values his life. Second, although the dog lover's inordinate concern for his pet may not itself affect the value of his heroic act, it would affect the value of his acts in more ordinary cases involving substantive relationships. For example, imagine that the fanatical dog lover gets a call from a friend who says her father just died and that she could use some support from family and friends. The dog lover says, "I will be right 
over; as luck would have it, my dog Muffy has stopped getting lonely when I go out, so I am happy to come over and stay as long as you want." This sort of response, and follow up responses clarifying that the dog lover values Muffy's maximal comfort over her friend's basic emotional welfare, are sure to leave the friend unhappy and wishing for better friends. More pertinently, as the core virtue ethical thesis predicts, the fanatic's action of coming over to comfort his friend (for good reasons) is less good and praiseworthy than the similar action of a better friend - one who values her friend's serious need over her dog's trivial comfort and who is therefore disposed to come over in the case in which her dog would be lonely in her absence. Here, as elsewhere, I think we care about the meaning of the actions of our friends, parents, bosses, etc. and this meaning is often largely a function of people's personal values, which are reflected in their dispositions to think, act, and feel.

Finally, I want to consider another case that Hurka gives us and that is amenable to a response like the one I gave to his soldier case:

...imagine that your companion stops to give $\$ 20$ to a homeless person, apparently from concern for that person for her own sake. Do you say, 'That was generous of you' or 'That was generous of you on condition that it issued from a stable disposition to act from similar motives in similar circumstances'? Again surely you say the former. Since your judgement is of virtuousness, it turns on your companion's motives rather than on any external features of her act. If you learn that she was acting only to impress you or some bystanders, you may grant that she acted rightly but will withdraw your attribution of generosity. But that attribution concerns only her current motives, apart from any connection to longer-lasting traits (Hurka 2006: 71).

Now when first reading this case we naturally assume that the companion values the $\$ 20$ and that in giving the bill she is therefore knowingly making a generous sacrifice. But just as the soldier might undervalue his life and that would at least diminish the courage of his action, the companion might undervalue the loss of $\$ 20$ and that would at least diminish the generosity of her action. For example if the person has been inducted into a strange religious cult, disvalues having money in her wallet, and is therefore disposed to give her money away to anyone who asks, then her act is less generous than it would be if she values what she gives away, and is therefore disposed to be less openhanded with her money. In each case, she may be proximally moved by awareness 
of the plight of the homeless person and give the bill solely in order to help him out, but the degree of generosity in her act hinges on how much she values what she gives away.

\section{From Personal Values to Personal Character}

My argument so far has focused on the claim that an agent's personal values can affect the value of her acts. My assumption has been that if this claim is granted then we can move rather simply to the virtue ethical thesis that dispositional character, understood as something that outstrips the motives, intentions, and emotions with which an agent acts in a particular case, can and often does affect the ethical value of that particular act. But the skeptics might grant my various claims about personal values affecting the value of acts and attack my assumption that these support the virtue ethical thesis; they could grant that personal values affect the value of acts but question the tie between personal values and dispositions. After all, I granted at the outset that an agent's intentions or reasons for acting are not logically or metaphysically tied to her dispositions, so the skeptic could reasonably demand that I justify the assumption that things are different when we turn to personal values. In Hurka's soldier case, for example, the skeptic could admit that the act's value is a function of both the soldier's intentions or reasons for acting and how much he values his life but then suggest that both of these factors are nondispositional. Why, in other words, couldn't the soldier's out-of-character courageous action involve both out-of-character intentions and out-of-character personal values? ${ }^{7}$

To assess this challenge, it is important to distinguish two different claims one could make about the connection between personal values and dispositions. The first, extreme claim is that our personal values at a time are logically or metaphysically tied to persistent or characteristic dispositions in a way that makes it impossible to act from outof-character values on one occasion. For example, one might claim that it is impossible for the soldier to value his life very much right before jumping on the grenade while being characteristically disposed to inordinately disvalue his life. Now, like the skeptic, I don't see why we should accept this strong view. I do think that in ordinary circumstances we may be justified in ruling out this kind of thing as a practical

\footnotetext{
${ }^{7}$ Thanks to Roger Crisp for pressing this objection.
} 
possibility. Moreover, in many cases evidence of one's persistent or characteristic personal values will be more accessible than evidence of one's values in a single case, so it may make sense to focus on gathering evidence of persistent values when working up an evaluation of an agent or her acts. But since we can't simply leap from those practical and epistemic points to any strong metaphysical or logical conclusions, I think we should grant to the skeptic that people can sometimes act from temporary, out-of-character personal values.

Luckily, there is a second, more moderate claim about personal values and their connection to dispositions to think, act, and feel. This is the claim that if someone values something at a time, then he is, at that time, disposed to value it in various ways. Take the soldier. If he happens to momentarily value his life a great deal, then, at that moment, he is disposed to protect his life, refuse to sacrifice it for small causes, feel sad at the prospect of his dying, and so forth. If he is not so disposed, then the claim that he values his life a great deal is simply false. In fact, having those dispositions is part of what it is for him to value his life a great deal (at that time) ${ }^{8}$

To see that these more moderate claims about the logical and metaphysical connection between valuing and being disposed are plausible, we can usefully reflect on a second case. Consider again Jane, who claims she values her friendship with Dan more than her career development. My contention is that this claim is true only if she is, at the time she makes the claim, disposed to judge the friendship more important, to choose it over career advancement, to feel bad if she fails to choose the friendship over her career advancement, etc. So if she claims to value the friendship more but at that very time is disposed to happily sacrifice Dan's happiness to get ahead, to feel glad about the results, etc. then her claim is false. Consider, in this connection, how odd it would be for Jane to say, "I value your friendship more than getting ahead; but, if I have to, I will stab you in the back to get ahead and I won't feel bad about it." This assertion flirts with self-contradiction just as my view predicts.

We have just seen that personal values at a time are themselves dispositional and that we therefore may legitimately move from the premise that personal values affect the value of acts to the core virtue ethical thesis, but the distinction between values at a time and values across time

\footnotetext{
${ }^{8}$ Of course sometimes something inhibits a disposition from manifesting itself so the man could value his life and have these dispositions even if they were never manifest in his life.
} 
suggests a new line of response that the skeptics could press in response to my argument. The skeptics could grant that while personal values at a time can and often do affect the value of acts, the same cannot be said of personal character, which is presumably a function of how an agent's values, beliefs, intentions, emotions, behavior, and so forth change over time. In other words, the skeptics could grant that I have established the personal values version of the core ethical thesis but still express skepticism about the personal character version. Moreover, they could point out that the personal character version of the core thesis is the one that most immediately comes to mind when someone claims that character affects the value of acts, and then argue that if virtue ethicists just stick with the personal values version of the core thesis, and disavow the personal character version, then it would be misleading for them to claim that their theories assign character an especially central theoretical role.

To fully assess this new skeptical attack and all the issues it raises, we would need to do two things. First, we would need to develop a full account of what personal character is - for example by asking whether character is fully determined by an agent's dispositional values or whether it also hinges on her success or failure to embody those in her behavior. Second, we would need to develop a typology of the various ways in which personal character can vary in quality and then discuss which types of variations can influence the value of acts. These are not tasks that I can hope to accomplish in the remaining space, of course, but I think I can say enough about the relevant issues to show that the fall back skeptical view, i.e. that variations in quality of personal character never affect the value of acts, is false.

\section{Personal Character and the Strong Virtue Ethical Thesis}

As noted at the end of the last section, personal character is clearly not just determined by what an agent values at a time; but what else it involves is a complicated matter. In general, I think we can say this much: personal character is partially a function of (a) the personal values that an agent is disposed to harbor and manifest at different times and (b) her dispositions to live up to or embody those values or not. To account for cases in which people fail to live up to their values, I also think we can usefully distinguish between how much someone values something and how much they care about it. To illustrate the distinction, consider the fact that many people care a lot about what their peers think about them and wish they cared less. Many of us know we 
care about our peers' approval more than we should and in specific instances may find ourselves doing bad things because we care about getting peer approval that is valueless, even by our own lights. So as this case illustrates, caring and valuing are distinct and can come apart; we can care a lot about getting something that we do not value at all.

The distinction between caring and valuing will help us develop a plausible account of personal character in part because it will allow us to explain many cases in which agents don't live up to or embody their values. Take Jim, who does not criticize his boss's racist and sexist remarks even though he values standing up in the face of such remarks more than he values being in his boss's good graces. We can explain this failure and Jim's more general lack of integrity by appeal to the fact that he cares more about being in his bosses good graces than he does about standing up to racism and sexism. In addition, the distinction between caring and valuing will also let us distinguish between people who harbor schizophrenic personal values and people who have more or less stable values but who fail to live up to those because of their weak character.

To further illustrate these claims, consider again Jane, who currently values her friendship with Dan more than her career advancement. It is possible that although Jane really does value Dan's friendship more than her career right now, she is also characteristically prone to value things differently at other times or in other contexts. Perhaps when she is at work and around her peers she values career advancement more than Dan's friendship but when at home, hanging out with Dan, she values his friendship more than climbing the ladder. In my view, there is no more reason to deny that people can have these kinds of schizophrenic personal values than there is reason to deny that people can have characteristically integrated values but, on odd occasions, harbor out-of character ones. Schizophrenic Jane's values shift from context to context, but she could develop a more stable set of values and still fail, out of weak character, to reliably choose her friendship over her career. For example even if she values her friendship more than her career advancement both at home and at work, she may be disposed to give in to pressure from her boss and let Dan down as a friend in various ways. She might just care about her boss's approval, or avoiding his angry outbursts, more than she thinks she should.

With these general remarks about the nature of personal character in mind, I want to turn to questions about personal character assessment. Our main goal in this section is to evaluate the claim that changes in the quality of an agent's dispositional personal character - and not just her 
personal values at a time - can and often do affect the value of acts; and I think personal character can indeed have this affect because it can affect the symbolic value or personal meaning of an act.

Here is an example: the ethical value of Randy's coming to the ball game to cheer his son on is in part a function of how much he values his relationship with his son and the opportunity to support him. Presumably Randy's son values his showing up and cheering for him in good part because of the symbolic value of those actions - the actions are valuable because they embody and signify something about how much Randy characteristically values his son and his relationship with him. So if Randy does not characteristically value his relationship with his son very much, and just temporarily values it a lot on one occasion, his action of showing up will carry less symbolic value than if he shows up and does characteristically value his son. If Randy for some odd reason temporarily and uncharacteristically values his son and their relationship when he shows up, his son might say, "Sure, right now he is all enthusiastic about supporting me and cheering me on and he is waxing poetic about how important family is; but just wait and see; when tomorrow rolls around things will be back to usual." We can naturally imagine him saying this to explain why he is only mildly pleased to see his Dad yelling in support from the sidelines and why his Dad's actions don't mean as much to him as they would if they were indicative of his deep values. By the same token, he would be more pleased if his Dad's action was symbolic of his characteristic values, and that is presumably because the act would then have more meaning or symbolic value.

If I am right, this example illustrates the general truth that personal character, understood as something that is a function of one's dispositions to value at various times, can and often does affect the value of acts, just as personal values at a time do. So the fall back skeptical line of response to my earlier argument about the significance of personal values at a time fails. As I have said a full discussion of the issues in this area would require a more developed account of personal character, but I will have to leave that for another occasion. What I will do in the remaining pages is explain why I don't think that the argument that I have just made about the affect of personal character on the value of acts is available to philosophers who adopt the reliable trait conception of character.

To begin, it is worth noting that we may value a friends' disposition to value us (or our friendship) independently of whether she has a more general and reliable trait to value friends (or 
friendship). By extension, we might value a friend's act of visiting us in the hospital because it symbolizes or expresses her loyalty to us, without thinking that the act symbolizes or expresses a general, reliable trait of being loyal. These points suggest that the personal values interpretation of personal character fits with the foregoing argument in a way that the reliable trait conception does not, but they also draw attention to the fact that our aretaic (roughly virtue and vice) judgments of people and their acts are often tied to bounded, local contexts that are roughly defined by their connections to some roles, projects, ideals, or relationships. A judgment about our friend's loyalty for example might focus on the personal values that she harbors and embodies in the context of our friendship, not in friendships or life in general. Put otherwise, aretaic judgments often rest on assessments of the personal character someone embodies in a local context instead of on her more global traits. This point is important to note because my examples in this paper suggest that it is primarily locally bounded aretaic judgments, grounded in facts about an agent's locally relevant personal values, that can justify the claim that facts about aretaic character affect the value of acts.

To further illustrate the way in which we regularly make locally bounded aretaic judgments and the fact that they are grounded in locally relevant personal values, imagine that you are thinking of hiring Jane and the letter of reference form asks me to describe her character. In this context, you are asking me to describe the facts about her behavior, emotions, traits, etc. that are indicative of the personal values that you can expect her to harbor and act on (or fail to act on) while at work. On reflection I might describe her as loyal, compassionate, and easygoing. If, by way of contrast, you are thinking of dating Jane and ask me to describe her character, I should describe a very different set of values and dispositions that are relevant in this different context. In assessing her as a prospective partner, I might say she is not very loyal or easy-going. Of course, the work related judgments about her being loyal and easy-going might still hold true and might be worth communicating if you wanted to enter into a long term relationship with Jane, but the main point is that her interactions with you as a partner would be liable to be affected by her degree of relationship-loyalty in a way that they would not be affected by her on the job loyalty. ${ }^{9}$

${ }^{9}$ Biographers may aspire to give complete descriptions of personal character, but this just highlights the fact that our ordinary assessments are most often local, not global. If MacIntyre (1981: 204ff) is right, there might be something bad about our tendency to make local but not global character assessments. I don't think this is the case, but cannot pursue the issue here. 
If what I have just suggested is correct then we can agree that an agent's degree of virtue or vice can and often does affect the value of her acts without accepting the reliable trait interpretation on which degrees of virtue and vice should be understood in terms of the reliability of the relevant traits. If that reliable trait interpretation is accepted, we have to say that the value of Jane's loyally defending Dan's name in the face of malicious gossip should vary depending on how reliable her disposition to be loyal is. And as we have seen, that is just the kind of claim that the skeptics rightly challenge; the value of Jane's sticking up for Dan does not depend, for example, on facts about whether she would betray her country in wartime or not. But once we adopt the personal values approach to thinking about character and notice that aretaic character assessments are often local, we have a more reasonable way to think about how aretaic character can bear on the value of acts. The basic idea is that we use virtue and vice terms to describe context-relative personal character and that can indeed affect the value of acts. If Jane is characteristically a loyal friend to Dan then her act of sticking up for Dan in the face of gossip may have more symbolic value or meaning than it would otherwise have; but facts about how loyal she is in other contexts (e.g. wartime) will not have similar significance. In sum, aretaic dispositional facts may in some cases track the value of acts, but that is only because they reflect some relevant personal values and not because they reflect generally reliable aretaic traits.

Before concluding, let me mention one other case involving symbolic value or meaning that is a bit harder to assess. I think the Randy and Jane cases show that facts about personal character can affect the meaning, and hence value, of acts, but these are cases involving personal relationships and it is no surprise that we care about the symbolic value of the ways that our friends, family members, partners, etc. interact with us. I want to now consider a case in which someone's more general ethical character might be thought to affect the value of her interactions with strangers.

Imagine that some stranger, who does not owe you anything, helps you out of a jam, perhaps by paying off some debt you have. You are initially grateful and think the act was very good, but then find out that your benefactor is an unrepentant racist who regularly helps out strangers in need, but only after checking to see whether they are of African descent. Now I can imagine some people thinking that the help you got in this case was in some way symbolically tainted because of the racist personal character of your benefactor. It seems too strong to say that by accepting the help you made yourself complicit in his racist agenda or that you became party 
to his plans, but it is entirely conceivable that one would dislike being associated with the racist by being his beneficiary, and for that reason conclude that it was a bad thing to have gotten his help. This implies, however, that you think that the act of his giving you the money is in some way worse because of the way it symbolically connects you to the racist's immoral character.

I end with the case involving the racist benefactor for several reasons. First, I think it illustrates how unclear the concepts of symbolic value and meaning are. The fact that they are unclear does not mean that they are bankrupt, but I want to admit that to fully rebuff the skeptical attack, a virtue ethicist who adopts the personal values approach needs to clarify the relevant concepts. Second, the racist benefactor case suggests that facts about an agent's ethical character can affect the value of her acts even if these are facts about how they would treat people who are not affected by the actions being judged. The ethical value of your interacting with me can depend on how your personal character disposes you to treat other people in some very different context. Finally, third, this case suggests that although meaning most obviously affects the value of acts in cases involving substantive relationships, it can also affect the value of acts between strangers.

\section{Conclusion}

I have argued that if virtue ethicists adopt a personal values conception of character instead of a reliable trait conception, then they can plausibly defend the core virtue ethical thesis. In fact, they can rightly maintain that personal character, (local) aretaic character, and personal values at a time can, and often do, affect the value of acts. Of course even if this thesis is true, virtue ethicists will need to do more to explain what they mean when they say that they give dispositional character a central or especially prominent role in their ethical theories and to defend the claim that their approach constitutes a genuine third method of ethics. But I hope that in this paper I have at least shown that these tasks can be sensibly pursued and that wholesale skepticism about the core virtue ethical thesis is unwarranted. ${ }^{10}$

\footnotetext{
${ }^{10}$ This paper was made possible through the support of a grant from The Character Project at Wake Forest University and the John Templeton Foundation. The opinions expressed in this publication are those of the author and do not necessarily reflect the views of The Character Project, Wake Forest University, or the John Templeton Foundation. I benefited from helpful feedback from the audience at the final Character Project conference, and also want to thank
} 
References

Anscombe, G. E. M. 1958. “Modern Moral Philosophy.” Philosophy 33, no. 124: 1-19.

Crisp, R. 2014. "A Third Method of Ethics?" Philosophy and Phenomenological Research, forthcoming; currently published on-line as an Early View article.

Hurka, T. 2006. "Virtuous Act, Virtuous Dispositions," Analysis 66: 69-76.

MacIntyre, Alasdair. After Virtue: A Study in Moral Theory, Third Edition. 3rd edition. Notre Dame, Ind: University of Notre Dame Press, 2007.

Markovits, J. 2010. "Acting for the Right Reasons," Philosophical Review 119: 201-42.

Scanlon, T. M. 2010. Moral Dimensions: Permissibility, Meaning, Blame. Cambridge, Mass.: Belknap Press.

Scheffler, Samuel. 2011. "Valuing." in Reasons and Recognition: Essays on the Philosophy of T. M. Scanlon, Wallace, Kumar, \& Freeman (ed), New York, NY: Oxford University Press, 2342

Slote, Michael. Morals from Motives. New York, NY: Oxford University Press, 2003.

Sverdlik, Steven. Motive and Rightness. New York, NY: Oxford University Press Oxford University Press, 2011.

Zyl, Liezl van. 2012. "Review of Steven Sverdlik, Motive and Rightness." Ethics 122, no. 3: $627-32$.

Roger Crisp, Tom Hurka, Rachana Kamtekar, Michael Slote, Ben Yelle, Dan Corrigan, Anita Kelly, and, especially, Christian Miller for very helpful comments or discussion. 